\title{
Contribution of new technologies to pedagogical interaction management in a class
}

\author{
Rémi Legrand \\ Université Pierre-et-Marie Curie (Paris VI) \\ Bur. C266 - 8 rue du Capitaine Scott \\ 75015 Paris - France \\ legrandr@ccr.jussieu.fr
}

\begin{abstract}
This paper presents how new technologies including wireless devices may improve the interaction management in face-to-face learning. The hardware and software required to implement new pedagogical functionalities are presented. We focus our study on different layers of annotation, aggregation of students' responses and uses of collaborative learning tools. An experiment schedule and the first results are presented in order to study the feasibility and interest of our approach in higher education.
\end{abstract}

\section{INTRODUCTION}

The interactions between the teacher and the students are central within face-to-face learning. However little of interaction is written down and kept for further use. In this paper, we propose to computerize some pedagogical interactions occurring in class, so that the results of the pedagogical activity could be stored. The progressive integration of information and communication technologies for education (ICTE) into face-to-face learning addresses the issue of their sensible use in order to adapt investments and to build innovative pedagogical processes. Our paper studies the contribution of computerized interactions during a class, and presents the hardware and software required to implement them. Computerized interactions should increase the stream of interactions and thus contribute to a better students' involvement [1,2].

Local networks in a pedagogical context have been widely developed, but are mainly dedicated to lab class. New technologies extend the use of ICTE to any kind of classroom. Among the reasons why they have been spread, we can quote the fast-expanding of wireless networks, the fall of the cost of hardware, and the use of new software easy-tocustomize. The remaining issues of security and capacity are to be dealt with and are less critical in our context. The devices considered here are a projector, an interactive whiteboard, laptops and Tablets PC which enable handwriting. All these devices may be connected through a wireless network. The crucial features of mobile devices are: easy to carry, easy to plug and easy to launch. Researchers experiment the use of handheld computers and Personal Digital Assistants (PDA) to equip the students (e.g. [1, 3-6]) in a wireless classroom. PDAs have obvious advantages over laptops and tablet PC: low cost (see Section 3) and small size. But they need specific tools, operating systems and software implementation. As far as possible, we choose

\author{
Michelle Joab \\ LIRMM, Université Montpellier II \\ 161 rue Ada \\ 34392 Montpellier cedex 5 - France \\ Michelle.Joab@lirmm.fr
}

standards (Operating systems, computer languages) and widespread devices. Taking into account spreading and versatility of laptops in higher Education, we choose to use them in our experiments.

Very early research was done exploring the pedagogical uses of the wireless classroom [7, 8]. In these Wireless Classroom, the students used laptops equipped with a wireless card, speakers and microphone; the teacher had a video camera, a microphone, a projector connected to his laptop. In addition, he may use a writing device. The classroom had several wireless access points. They encountered many technical locks which slowed down its development. For example, the performance of the wireless networks was unacceptable to deal with the transfer of multimedia interactive documents mixing images, video, audio (from 2Mbps in 1998 to $10 \mathrm{Mbps}$ today)... The technology was not mature enough. We can quote for example, the weak reliability of batteries and the weak quality of the drawing devices.

Today, mobile and wireless devices are extensively included in new pedagogical organizations [9, 10]. The frontiers of the classroom are not clearly defined $[4,6,11]$. In the Ubi-Learn Project [12], the students may be inside or outside of the virtual class. They are equipped with a computer or any mobile device. They can interact with other students and any professor.

In the next section, we describe the contributions of these technologies to the pedagogical activities in a class. Section 3 presents equipment and human costs involved. Section 4 presents an experiment schedule and the results of our first experiments in order to study the feasibility and interest of our approach.

\section{CONTRIBUTIONS OF NEW TECHNOLOGIES TO PEDAGOGICAL ACTIVITIES IN A CLASS}

The interactions in a classroom are central within face-toface learning. However little of this interaction is written down and kept for further use. Within a fully equipped classroom, the teacher projects slides and comments on them with annotations arising from the interaction with the students. A projector is connected (with a wireless connection) to the teacher's tablet PC, so he can move through the classroom with the latter. 


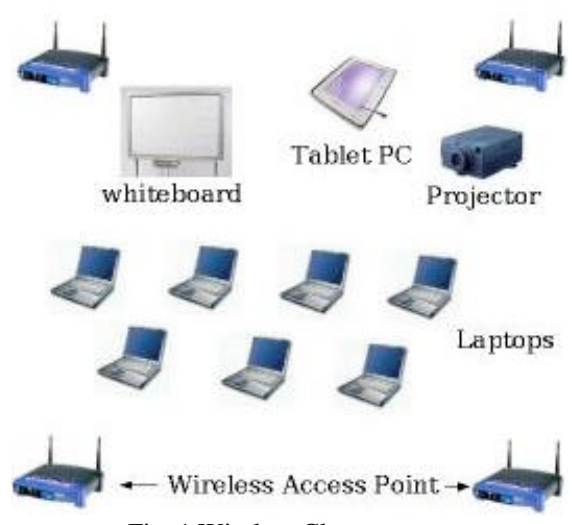

Fig. 1 Wireless Classroom

To handwrite annotations, he uses his tablet PC (Fig. 1) or an interactive whiteboard (Fig. 2). He can also associate oral annotations to a slide, following an interaction. The teacher assigns a status to an annotation according to its final use: forwarded to the students without modifications, corrected then forwarded, considered anecdotal and not forwarded.

In an equipped classroom, students use their laptop to visualize and annotate the current slide displayed by the projector (Fig. 1 and Fig. 2). They can also go back to the previous slides. They manage three layers of documents: the initial slides displayed by the teacher, the annotations given by the teacher and immediately forwarded, and their own annotations. A few other tools are needed to manage annotations and layers when they overlap, or to allow a student to send an annotation to others. The oral and handwritten annotations are stored either as images and sounds, or after being recognized by a dedicated program.

In CoolCom [13, 14], an annotation tool is implemented on a PDA. Students make private annotations to public slides offered by the teacher. These annotations can be visible or invisible. The teacher allows the presentation of some student's annotations on the whiteboard. Taking into account the small size of the screen, the students can annotate only a partial view of the global workspace on their PDA. The students may also exchange their ideas and hypotheses peerto-peer between the mobile applications.

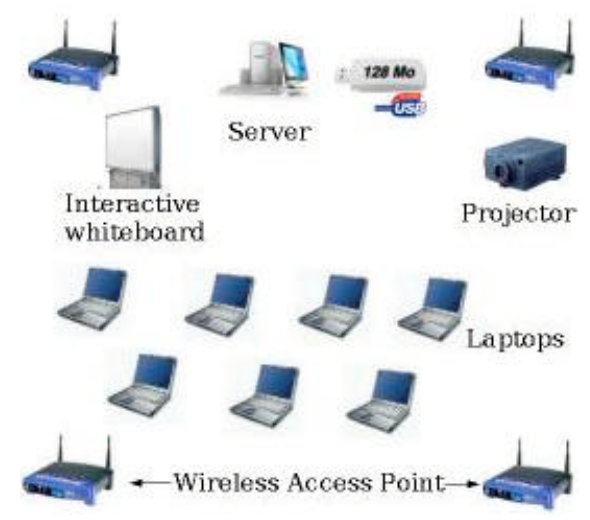

Fig. 2. Wireless Classroom with e-board
Students can ask questions from their laptop. The teacher sees them on a control panel with the name of the student. He decides whether he displays them on the interactive whiteboard. Then, the teacher selects the questions he wants to answer and/or store. It is possible for the students to join in to a question displayed on the interactive whiteboard, to support it. Chang, Sheu and Chan [11] control more closely the operations performed with each student's mobile device. For instance, teachers can access to students' notes.

Some questions should be collectively interpreted, such as those expressing a lack of understanding. They are anonymous questions and are indicated to the teacher through a threshold mechanism. Liu et al. [2] use indicators in WITEC (Wireless Technology Enhanced Classroom). These indicators highlight each student status: green for on-line, yellow for lagging connection, black for disconnection, red for requesting help. Nevertheless, the control panel do not aggregate individual data. Roschelle [15] analyzes the capability of Classroom response systems to monitor the student's evolving understanding. A classroom response system aggregates students' answers before and after discussion. He highlights the role of technology including anonymity and speed of response collection. Davis [3] studies the effects of anonymity in students' answers on student engagement in the classroom.

In our equipped classroom, a student can directly ask a question to peers through the network, because their answers are often more simple to understand. The control panel is to be experimented to assess the additional cognitive workload required from the teacher and the students. We also have to evaluate how much these functionalities help the course of the class.

At the Kentucky University, the Wireless Project [7, 8] experiments very near functionalities for sharing annotations, questions, and answers on a whiteboard. Unfortunately, the project faced many technical difficulties in 1998 which slowed down any spreading of wireless classrooms.

Our study is concerned with collaborative work in pedagogical situations. For instance, during recitation class, several correct solutions could rise from proposals made by students. This collaborative work and its associated discussion must be preserved. Indeed, the arguments exchanged and the choices carried out are as important as the solution. After the discussion, it is essential to synthesize each solution studied, to guarantee their global coherence and consistency. The use of collaborative work software in a network based classroom enables to reach the following goals: the working out of solutions for each group of students, communication from one group to other groups, global discussion, shared annotations to exchange arguments and proposals in order to improve the solution. Following this first step, each group has to take into account the global discussion and adapt each solution in order to make it coherent with it. 
DiGiano, Yarnall, Roschelle, Tatar and Manley define eight Collaboration Design Patterns for classroom activities in a wireless classroom [9, 10]. Each pattern describes a collaborative pedagogical scenario. Mainly, it specifies: the problem that the pattern addresses, an example, the context in which the pattern may apply, the solution, the implementation (the solution principle), and the technical requirements. For example, the "Exchange Template" shows how a structured template facilitate the exchange of work between students. Design Patterns demonstrate their usefulness for software engineering [16]. As every generic description of knowledge, patterns are first extracted while analyzing many pedagogical scenarios. Then, patterns are validated through designing collaborative pedagogical activities. In any case, they convey best practices for collaborative learning in wireless classrooms.

Much attention must be paid to communication aspects in the wireless classroom. Many problems raise from the use of Internet in the wireless classroom [15]. Teachers want to control communications and more generally students' attention. We agree with this choice and focus mainly on locally networked activities.

Roschelle and Pea [1] underline the two layers of communications in a wireless classroom, technology-based communication and interpersonal communication, whose respective roles have yet to be studied.

\section{EQUIPMENT AND HUMAN COSTS}

Equipment and human costs are successively presented below.

\section{A. Equipment costs}

We assess the cost to fully equip a wireless classroom from the costs of atomic components detailed in the table below. They give a rough estimate of today, as computer hardware is improving very fast. From the following figures, we estimate the cost of a classroom designed for 30 students. Each student uses a laptop or a Tablet PC. The teacher uses a Tablet PC, an interactive whiteboard and a projector. In addition, we need a few access points connected to Internet. According to that, the total cost amounts to $67500 €(1 €=$ $1,2 \$$ ).

Actually, this cost estimate does not correspond to equip a classroom in the future. Indeed, we consider that, in the next years, every student will have its own laptop, the same way he/she has a mobile phone today.

\begin{tabular}{|l|l|}
\hline \multicolumn{1}{|c|}{ Device } & \multicolumn{1}{c|}{ Cost } \\
\hline Laptop with a WIFI card & from 1000 to $2000 €$ \\
\hline Tablet PC with a WIFI card & from 2000 to $3000 €$ \\
\hline Personal Digital Assistant & from 300 to $800 €$ \\
\hline WIFI card & about $80 €$ \\
\hline $\begin{array}{l}\text { Interactive whiteboard } \\
\text { (for a recitation classroom) }\end{array}$ & from 1000 to $2000 €$ \\
\hline WIFI access point & from 100 to $300 €$ \\
\hline WEB Camera & $100 €$ \\
\hline
\end{tabular}

\begin{tabular}{|l|l|}
\hline Headphones and microphone & $30 €$ \\
\hline Projector & from 1500 to $3000 €$ \\
\hline
\end{tabular}

Fig. 3. Device Costs

The personal equipment of students is taken into account in the French program entitled «Universités numériques en region » (wired campus in regions) launched in 2003. Its aims is to develop a comprehensive set of wired services devoted to all the university users in each region. An important chapter of this program concerns the equipment of the students. For instance in the «Rhône-Alpes » region, a plan (http://www.pampampam.net) initiated by the Greco ${ }^{1}$ aims to offer special rates to the students and teachers. The prices proposed are within the margin given above: $1000 €$ (VAT included) for a laptop with office tools, $1500 €$ for a laptop with scientific or multimedia tools, and $1900 €$ for a laptop with mobile tools. Moreover, specific consumer credits are proposed to the students.

Insofar as the students have their own laptop, the overcost due to the wireless class will be reduced to the set up of a wireless network throughout the university, with interactive whiteboards and projectors. All these devices cost less than $10000 €$ per classroom.

Above all, the wireless technology permits to wire old buildings and are very well suited to the mobility of students and teachers activities.

\section{B. Human costs}

Once a classroom installation is realized, extra uses are possible. As some interactions are automatized and required less interventions from the teacher, so more students can be added in the class. Even students at distant locations can be synchronously connected to the class through Internet network. For these distant students, this framework is a synchronous virtual class, close to a Learning Management System such as LearningSpace 5. That would be adapted to lecture class where the teachers do not interact much with the students. The extension of wireless class which incorporates distant students could be seen as a way to reduce the cost of teaching.

Our approach is the opposite view since we consider that wired classes must be developed in order to improve the interactions. In fact, students generally prefer to attend classes rather than to study from a CD-ROM. They save time, except in particular cases such as those who are living far from the university, and those who are repeating their year. So, the number of students attending a class does not change whether the lecture slides are available. Contrary to distant learning which enables economies of scale, the wireless class does not reduce costs except for instance when two universities organize a common course so they avoid travelling expenses.

To train the teachers is the main difficulty encountered. They must be convinced by the contribution coming from

\footnotetext{
${ }^{1}$ Greco (Grenoble Universités Campus Ouvert) http://greco.grenet.fr/
} 
wired campus. They must be motivated to accept to devote their time to that training. The awareness of the importance of a good training will contribute to a better implementation of pedagogical innovations. The cost of this training must be integrated in the global evaluation.

The pedagogical activities described in the previous section produce new annotations coming from the interactions which occurred during the class. These annotations must be treated in anticipation of the future uses of the course. To edit and incorporate these annotations is easier because the teacher has stored them. So, the teacher saves time. However, editing an annotation could be tedious and inappropriate to the future courses. The overall waste or gain of time is questionable.

\section{EXPERIMENT SCHEDULE AND FIRST RESULTS}

The pedagogical situations presented in Section 2 do not require heavy installation in terms of equipment or wiring.

They rely on existing software (shared editors, handwriting and oral recognition) or small software easy to develop (control panel). We have worked out an experiment schedule to validate the situations encountered by the students and teachers. Each experimental variable is tested in order to validate separately each pedagogical hypothesis. The validation process focuses on the technical feasibility, the usability of devices, the quality and number of pedagogical interactions.

\section{A. Experiment schedule}

During the first half of the year 2004, at the university of Montpellier 2 (France), we are carrying out the following experiments based on different requirements: use of a tablet PC by the teacher to communicate with students in a class situation, and use of synchronous collaborative work software in a class situation.

A wireless network will be installed in some buildings by summer time. Next September, we hope that we will be able to test the whole wireless classroom.

We will also develop and test the applications in charge of the control panel and in charge of sharing of annotations. After these experiments, we will be able to suggest a software requirements specification to generalize such devices.

The first experiment makes use of a Tablet PC connected to a projector to communicate with students in a class situation. The Tablet PC is used according to their previous ways of teaching. This experiment is conducted in two pedagogical situations: a lecture class and a recitation class.

\section{B. First results concerning a lecture class}

In a lecture class, some teachers are using the Tablet PC. Mainly, they teach mathematics or physics and make an intensive use of formula rather tedious to edit. So they take advantage of the opportunity to handwrite them on their Tablet PC. They handwrite either during the class or in advance, as they are afraid to use it in real time. Probably, they fear that their handwriting could be unreadable or that it will take more time than writing on the blackboard. Once written the course materials, the teachers upload the file on an open source course management system, Claroline (http://www.claroline.net/), in order to make them available to the students.

For computer science courses, teachers often use software as MS PowerPoint to prepare slides before the class. With a Tablet PC, they project slides and comment on them with handwritten annotations arising from the interaction with the students.

\begin{tabular}{|l|l|l|l|l|l|}
\hline $\mathrm{N}^{\circ}$ & $\mathrm{H}$ & Int. & TEXTE & Th. & An. \\
\hline I12 & $15: 24$ & A1 & $\begin{array}{l}\text { En fait, je pense à un } \\
\text { mode d'évaluation } \\
\text { ressemblant à } \\
\text { l'évaluation du code de la } \\
\text { route à l'examen du } \\
\text { permis de conduire. }\end{array}$ & & \\
\hline I18 & $15: 27$ & A13 & $\begin{array}{l}\text { Faire un examen } \\
\text { ressemblant au permis de } \\
\text { conduire paraît être en } \\
\text { effet une bonne idée. }\end{array}$ & & \\
\hline
\end{tabular}

Fig. 4. Slides prepared before the class.

We observe that teachers appreciate written marks such as arrows, circles or highlighting items combined with oral intonations during the class in order to catch the student's attention. These marks stress the important items during the class and are not stored.

We notice that the student are also interested in Tablet PC facilities. It is a promising sign for the next step of our experiments.

\section{First results concerning a recitation class}

In a recitation class, we tested another class situation. Teachers use a Tablet PC to gather and synthesize the student responses. The experiment took place during a recitation class devoted to e-learning which focuses on different analysis of a forum. Figures 4 and 5 highlight a linguistic analysis based on Speech Acts [17, 18].

Figure 4 shows a table extracted from data gathered in a forum. Each utterance is described by a reference number (first column), a date (second column), a speaker (third column), a content (fourth column), a focus (fifth column) and an analysis (sixth column). During the class, the students have to discuss and to identify the focus and the speech acts involved in each utterance.

The teacher highlights the focus in the content column, handwrites the focus identified in the fifth column, draws an arrow from the content to the focus and finally handwrites the speech act in the sixth column (Fig. 5).

After the class, the completed slides are uploaded on the Course Management System Claroline. The results of the interaction during the class are stored at the end of the class. The trace of the interaction between the teacher and the students is stored on the fly with significant drawings. 


\section{First results concerning a collaborative work}

The second experiment is focussed on synchronous collaborative work. We try the Virtual Classroom tool in the Learning Management System LearningSpace5. It takes place in a laboratory classroom. Each student is connected through the wired network (we don't yet have at our disposal the wireless network). He/she has a microphone, a webcam and headphones connected to his/her computer. Students try the Virtual Classroom while working on a collaborative task: building a working plan for a software engineering process. The experiment aims at assessing the usability of the Virtual Classroom software in the wireless classroom. We have mixed feelings about this experiment.

\begin{tabular}{|c|c|c|c|c|c|}
\hline $\mathrm{N}^{\circ}$ & $\mathrm{H}$ & Int. & TEXTE & Th. & An. \\
\hline $\mathrm{I} 12$ & $15: 24$ & $\bar{A} 1$ & $\begin{array}{l}\text { En fait, je pense à un } \\
\text { mode d'évaluation } \\
\text { ressemblant à } \\
\text { l'évaluation du code de la } \\
\text { route à l'examen du } \\
\text { permis de conduire }\end{array}$ & $\begin{array}{l}\text { Hhit } \\
\text { th } \\
1.2\end{array}$ & $\begin{array}{l}5 \\
y \\
n \\
r \\
n\end{array}$ \\
\hline I18 & $15: 27$ & A13 & $\begin{array}{l}\text { Faire un examen } \\
\text { ressemblant au permis de } \\
\text { conduire paraît être en } \\
\text { effet une bonne idée. }\end{array}$ & $\begin{array}{l}4.4 \\
11.2\end{array}$ & $\begin{array}{l}a \\
p \\
p \\
p \\
z \\
0 \\
b \\
a \\
t \\
1 \\
0 \\
n\end{array}$ \\
\hline
\end{tabular}

Fig. 5. Results of the discussion.

First, the audio devices are essential for the collaborative tasks involved but they are not convenient in a classroom. When the teacher customizes the Virtual Classroom of LearningSpace 5 in order to allow every student to speak in turn, the control is given to the first speaker. As the microphones catch background noises, the speaker is not clearly identified. The Chat tool may be good enough to communicate. The Virtual Class enables sharing applications. The user control provided is not smooth enough for collaborative work. We have to try other collaborative tools which will be performed through the wireless network.

\section{CONCLUSION}

We are aware of the issues raised by our proposals. The motivation of the teachers is essential. New aspects of their activities must be well considered: the workload involved, the copyright and broadcasting rules attached to the documents, the evaluation of teacher's work.

We studied how new technologies including wireless devices may improve the interaction management in face-toface learning. The current hardware and software required to implement new pedagogical functionalities are low cost, widely spread, user friendly and efficient. Among computerized interactions, layers of annotation, aggregation of students' responses and uses of collaborative learning tools are promising. Before expanding wireless classrooms, further experiments have to be done in order to validate our working hypotheses.

\section{REFERENCES}

[1] J. Roschelle and R. Pea, "A walk on the WILD side:How wireless handhelds may change computer-supported collaborative learning," International Journal of Cognition and Technology, vol. 1, pp. 145-168, 2002.

[2] T. C. Liu, H. Y. Wang, J. K. Liang, T. W. Chan, H. W. Ko, and J. C. Yang, "Wireless and mobile technologies to enhance teaching and learning," Journal of Computer Assisted Learning, vol. 19, pp. 371382, 2003.

[3] S. Davis, "Observations in classrooms using a network of handheld devices," Journal of Computer Assisted Learning, vol. 19, pp. 298298, 2003.

[4] Y. S. Chen, T. C. Kao, and J. P. Sheu, "A mobile learning system for scaffolding bird watching learning," Journal of Computer Assisted Learning, vol. 19, pp. 347-359, 2003.

[5] O. Smørdal and J. Gregory, "Personal Digital Assistants in medical education and practice," Journal of Computer Assisted Learning, vol. 19, pp. 320-329, 2003.

[6] S. Hsi, "A study of user experiences mediated by nomadic web content in a museum," Journal of Computer Assisted Learning, vol. 19, pp. 308-319, 2003.

[7] J. Griffioen, W. B. Seales, and J. E. J. Lumpp, "Teaching in realtime wireless classrooms," presented at FIE-'98. 28th-Annual-Frontiersin-Education-Conference. Moving from 'Teacher Centered' to 'Learner Centered' Education, Tempe, AZ, USA, 1998.

[8] J. Griffioen, W. B. Seales, J. E. J. Lumpp, and K. T., "Experience Developing Wireless Networks for Interactive Multimedia Instruction," presented at FIE-'98. 28th-Annual-Frontiers-inEducation-Conference. Moving from 'Teacher Centered' to 'Learner Centered' Education, Tempe, AZ, USA, 1998.

[9] C. DiGiano, L. Yarnall, C. Patton, J. Roschelle, D. Tatar, and M. Manley, "Collaboration design patterns: conceptual tools for planning for the wireless classroom," presented at IEEE International Workshop on Wireless and Mobile Technologies in Education, Vaxjo, Sweden, 2002.

[10] C. DiGiano, L. Yarnall, C. Patton, J. Roschelle, D. Tatar, and M. Manley, "Conceptual tools for planning for the wireless classroom," Journal of Computer Assisted Learning, vol. 19, pp. 284-297, 2003.

[11] C. Y. Chang, J. P. Sheu, and T. W. Chan, "Concept and design of Ad Hoc and Mobile classrooms," Journal of Computer Assisted Learning, vol. 19, pp. 336-346, 2003.

[12] M. Laroussi, "New e-learning services based on mobile and ubiquitous computing: Ubi-Learn project," presented at CALIE 04 Computer Aided Learning in Engineering Education, Grenoble, France, 2004.

[13] N. Pinkwart, H. U. Hoppe, L. Bollen, and E. Fuhlrott, "GroupOriented modeling tools with heterogeneous semantics," presented at Intelligent Tutoring Systems 2002, Biarritz, France, 2002.

[14] N. Pinkwart, H. U. Hoppe, M. Milrad, and J. Perez, "Educational scenarios for cooperative use of Personal Digital Assistants," Journal of Computer Assisted Learning, vol. 19, pp. 383-391, 2003.

[15] J. Roschelle, "Keynote paper: Unlocking the learning value of wireless mobile devices," Journal of Computer Assisted Learning, vol. 19, pp. 260-272, 2003.

[16] E. Gamma, Design Patterns: Elements of Reusable ObkectOriented Software: Addison-Wesley, 1995.

[17] J. L. Austin, How to do things with words. Cambridge: Mass. Harvard University Press, 1962.

[18] J. R. Searle, Speech Acts. Cambridge: Cambridge University Press, 1969. 